\title{
ADVANCING AIR AND AIR DEFENCE CAPABILITIES: WHAT AND HOW?
}

New security challenges and advances in technology - sensors, communications and information technologies in particular-impact the development of advanced air and air defence capabilities and the way air forces are organized and equipped for effective performance of their roles. Advances of transport technologies, sensor systems, and unmanned air vehicles of increasing variety all create opportunities hardly envisioned only a decade ago. Air forces around the world utilize some of these new technological opportunities to enhance existing and develop new transport, reconnaissance, C2 and strike capabilities and deal effectively with opponents on the modern 'battlefield' and prove their worth vis a vis sister services.

And yet, the major interest of aviators, other military, defence civilians, observers and many contractors is on the development of the fighter aviation, often seen as a symbol of the air force as a distinct service and a capability of crucial importance for and a sign of national sovereignty. That is particularly visible when the existing fighter aircraft is coming to the end of their useful life cycle and countries, such as the new NATO members, face significant interoperability challenges. Decisions what type of fighter aircraft to acquire, how to acquire it, and even whether to maintain a fighter capability in the national forces always enjoy the attention of both the expert community and the public. These decisions are becoming particularly challenging for smaller countries in times of economic downturn and shrinking defence budgets.

To reflect on this problem, discuss requirements and share experience, on 30 April 2010 the AFCEA-Varna Chapter held an international conference in Plovdiv, Bulgaria under the title "Role and Importance of the Future Air Force Fighter for the National and Collective Security." Major General Constantin Popov, Chief of the Bulgarian Air Force, and fighter pilot himself, was among the keynote speakers. He is also Guest Editor of this special issue of Information \& Security.

The first section of this volume looks at considerations in making decisions in defence investments, in particular investments in advanced air and air defence capabilities. Four of the papers in this section are contributed by experienced military avia- 
tors currently taking senior positions with impact on decisions to acquire advanced air capabilities, who present a spectrum of considerations with major impact on eventual decisions to procure a new fighter aircraft and on the selection of a platform among the options available on the world market.

First, MG Popov outlines the major reasons for maintaining a fighter capability in the Bulgarian armed forces and the requirements the future fighter has to meet. Then Air Fleet General Alexandru-Petru Găluşcă from the Romanian Air Force presents the requirements to the future fighter Romania has formulated, and the way in which it intends to meet these requirements through a formalised capabilities generation process. In the third paper, contributed by another fighter pilot, Brigadier General Patrick Wouters, currently with the NATO International Military Staff, examines the evolving requirements towards alliance air forces and emphasises several factors with an important impact on procurement decisions. He underlines the advantages of the cooperation among allies in the procurement and the maintenance of a fighter capability, as well as in deploying such capabilities to distant theatres of operations. Brigadier General Mark Schissler from the US Air Forces in Europe wraps up this discussion, emphasising again that cooperation and partnerships among allies are key in the search for effective and efficient solutions in delivering advanced air capabilities.

There was a general agreement that countries like Bulgaria and Romania will continue to maintain a fighter capability, replacing their legacy aircraft with off-the-shelf platforms that guarantee interoperability with the air forces of NATO member countries both in the air defence of the territories of NATO members and in expeditionary operations.

Representatives of several first and second tier aerospace and defence contractors added to the discussion presenting their technologies and products to the participants in the conference and other attendees to the accompanying exhibition. One of these presentations was of particular importance to the discussion on the need for a multirole fighter capability and the factors impacting the respective decisions. Daniel Boestad from "Saab Bulgaria" posed six questions that the leadership of a national defence organization has to answer before buying a fighter jet and presented the view of Saab. The six questions are as follows:

1. Direct purchase or an open tender process?

It is assumed that an open tender process guarantees transparency of decision-making. In addition, EU regulations recommend an open tender process. Such procurement process would facilitate finding the best possible option and the best possible price for the buyer. 
2. Second-hand or new fighters?

There is evidence that second-hand is not necessarily cheaper than acquiring new fighters. For example, Romania has recently been offered 24 new Gripen for the same price as 24 second-hand refurbished block 25 F-16. Also, delivery time is not necessarily quicker for second-hand than for new aircraft. In the example of the Czech Republic Gripen was delivered in 11 months. Another consideration is that new aircraft are more capable and more upgradeable compared to second-hand. They will have a far lower operational cost and a higher availability than old aircraft. Finally, with a second-hand alternative there is a need to change aircraft type again within 10-15 years, while new fighters would be in service for at least thirty years.

3. Joint purchase?

Every country needs its own basic logistics package. There is evidence, e.g. from the US Air Force and the US Navy, that a healthy mix of platforms is actually good and might improve training. There are plenty of different platforms within NATO today, all of them performing exercises and co-operating. Hence, each country should decide what is best for itself.

4. Does the offer include a financial solution?

The financial solution is the only way to tailor the expense of a fighter purchase to the national budget. Grace periods and annual payments would help the buyer to start the process earlier. Lease options could be a very competitive option.

5. Is offset really necessary?

Most countries in the world require offset. Offset will bring foreign investments and new jobs to the country procuring a fighter aircraft, and will boost defence and civil industry through new technology. Saab's track record includes more than $20 \mathrm{Bn} €$ offsets to more than 30 countries. For example, the procurement of 14 Gripen aircraft by Hungary was accompanied by offset agreements of $700 \mathrm{M} €$ Foreign Direct Investments and export, creating 10000 jobs in the country.

6. Is the decision to acquire a fighter really a political issue?

No, it is mainly an economic issue. Strategic partnerships between the buyer and other countries will continue to form despite the choice of fighter aircraft.

Other company representatives informed the conference on advanced training, simulation, and communications technologies, allowing significant - and efficient-increase of air and air defence capabilities.

Contributor of the final paper in the first section of this volume is Major General (Ret.) Kiril Maznev, Head of the Offsets Department of the Ministry of Economy, Energy, and Tourism of the Republic of Bulgaria, who informed the conference participants on recent amendments to national offset regulations. Three of these deserve 
special mention: first, the recognition of the so called 'pre-offsets,' i.e. investments made in the country prior to signing a defence contract; second, the opportunity to transfer offset obligations among companies; and third, the priority on investments in the Bulgarian defence industry and R\&D organizations that facilitate the country's integration in the European defence technological and industrial base.

The second section of this volume presents original contributions to decision-support concepts, frameworks, methods and tools applicable to the topic of advancing air and air defence capabilities.

In the first of the papers, Major General (Ret.) Sabi Sabev examines the concept of air expeditionary packages and suggests that for the smaller among the NATO members, in particular those that joined NATO in recent waves of enlargement, the development and deployment of expeditionary air capabilities is crucial for the transformation of their air forces. He provides numerous examples, emphasising models of multinational, cooperative development and employment of air capabilities in distant theatres of operation.

The two following papers present comprehensive approaches to supporting investment decisions, with examples on the development of air capabilities in current and foreseen force development environment. First, experienced analysts from the Strategic Studies Group, Strategic Planning at Lockheed Martin Aeronautics Company present an easy to grasp and yet comprehensive decision making process, supported by advanced decision support methods and tools, all combined in the Force Matrix Model $^{\mathrm{TM}}$.

Next, a team from the Ajou University, South Korea presents an integrated capability framework that relates operational and capability development views, organizational, material systems and resource aspects of investment decisions. On that basis, the team builds a methodology supporting the prioritization of required capabilities, and the corresponding investment options, thus supporting resource constraint decision making. The framework and the methodology are applied to the prioritization of investments in air missile defence.

The next article, contributed by Venelin Georgiev-an expert in defence resource management and acquisition - treats the analysis of acquisition alternatives, adding assessment of affordability to traditional AoA approaches. That enhancement of an already powerful tool provides decision makers with opportunities for a rational and transparent translation of fiscal realities, along with other factors, in investment decisions.

The final paper is contributed by Marco Bartolozzi from the NATO C3 Agency. It presents several advanced technological developments, with focus on air defence 
command and control, and emphasises the benefits of multinational cooperation in the development of respective capabilities. Mr. Bartolozzi provides evidence of the positive impact the agency has played in the acquisition of advanced air defence capabilities and confirms its readiness to contribute to the enhancement of capabilities of NATO, member countries and partners, in particular in the region of South East Europe.

We believe that this I\&S volume will contribute to the understanding of the interplay between evolving security challenges, innovative strategic and operational thinking, and advances in technologies - both specially developed for military use and spinoffs from other domains. We intend to continue tracking and, where possible, foreseeing the interaction between advanced technologies and the development of capabilities that provide competitive advantages in a fluid environment. We intent to revisit the issue of air and air defence capabilities in the near future and to cover, among other issues, advances in unmanned aerial vehicles, air- and space-based surveillance and reconnaissance, logistics, training and simulation and their impact on doctrine and organization of air forces.

Todor Tagarev, Editor-in-Chief

Information \& Security: An International Journal 